\title{
Research on the Occupational Well-being of Student Affairs Administrators in Colleges and Universities
}

\author{
Yan Lou \\ School of Humanities \\ Zhejiang University \\ Hangzhou, China
}

\begin{abstract}
Student affairs administrators play an important role in the growth of students, so it needs to pay attention to their occupational well-being in order to better help their career development. Based on the understanding of the concept of well-being and the overview on its present situation, this paper focuses on analyzing the factors influencing the occupational well-being of student affairs administrators, and puts forward corresponding strategies for improving their occupational well-being.
\end{abstract}

Keywords—student training; student affairs administrators; occupational well-being

\section{INTRODUCTION}

Student affairs administrators are of significance in the growth of students, because they are the helper and supporter for students' development, the manager and executor of student affairs and the advisor and counselor for students' psychological problems. They support the development of students in terms of comprehensive quality promotion and professional knowledge learning. Therefore, all universities should strengthen the construction of administrators' ranks, so as to provide a strong organizational guarantee for the management of student affairs.

The student affairs administrators' ranks in Chinese Colleges and Universities (hereinafter referred to as Universities) are actually the ranks composed of counselors. In recent years, these ranks have developed very quickly, so the Ministry of Education has successively promulgated several policy documents and formulated a series of measures on aspects of ideological understanding, system mechanism, policy clarification and talents training, in order to earnestly strengthen the counselors' ranks construction. China's all universities are also actively taking measures to innovate the management system of the counselors' ranks, explore the professional development of counselors and improve the overall level of the counselors' ranks. Through the reform and exploration in recent years, the career of counselors has been strengthened on the aspects of the position, system and management. However, these institutional guarantees and theoretical researches are still focusing on the system construction rather than paying enough attention on the individual needs of the counselors' ranks. For instance, their own internal needs and the vision about their self-improvement and value realization are rarely concerned.

Counselors are the teachers' ranks with the most frequent contacts and the closest relationships to university students and the former also affects the latter most profoundly. They play a very important role in guiding the students' physical and mental development and forming the latter's values. The attitude of counselors to life and occupation, to a certain extent, affects students' attitude towards life and personal development. Therefore, the construction of the counselors' ranks must carry out the "people-oriented" concept and regard the counselors as the main body, pay attention to the subjective demands and the spiritual world of them, and pay attention to the promotion of occupational well-being of these counselors.

\section{THE INTERPRETATION OF CONCEPT: SUBJECTIVE WELL-BEING AND OCCUPATIONAL WELL-BEING}

The study on well-being arose in the United States in the 1950s. Wanner Wilson's "Correlates of Avowed Happiness" for the first time made a systematic theoretical elaboration of well-being, thus opening up the academic community's study on the well-being. After that, the theoretical and empirical researches on happiness emerged in large quantities, focusing on subjective well-being (SWB) and gradually forming a consensus on subjective well-being. As a subjective psychological feeling, well-being is not only a research aspect of psychology, but also involves many factors such as politics, economy, culture and society. Therefore, on the basis of numerous studies on subjective well-being, it has formed a number of research branches, such as occupational well-being, urban well-being and cultural well-being.

On the definition of occupational well-being, domestic and foreign scholars have not yet reached a consensus. Joan E.van. Horn and others believe that occupational well-being refers to an individual's positive evaluation on all aspects of his/her own work, involving emotion, motivation, behavior, cognition, physical and mental well-being aspects. 1 It is also argued that the sense of

Joan E.van Horn; Taris, Toon W; Schaufeli , Wilmar B; Schreurs, Paul J G. The structure of occupational well-being: A study among Dutch 
occupational well-being refers to the continuing happiness experienced by the subject serving in a particular occupation based on his/her needs being satisfied, potential being played and strength being enhanced. However, most of current mainstream definitions on counselor's occupational wellbeing merely emphasize the subjective experience, selfsatisfaction and professional identity.

Ma Ting suggested that the occupational well-being of university counselors refers to "a sense of balance and comfort in each dimension of the counselor's professional life and a harmonious experience between these teachers' physiques and minds. As far as its essence is concerned, the counselor's occupational well-being lies in the full realization of self-worth."

On the basis of predecessors' researches, we interpret the counselor's occupational well-being as: a kind of continuous and stable happiness sense which is produced by the counselors' dedication to the ideological and political education as well as their needs being satisfied, potential being played and professional development being strengthened. The counselor's occupational well-being includes both material and spiritual aspects, of which the spiritual aspect, especially the satisfaction brought by the growth of students, plays a decisive role in the counselor's occupational well-being.

\section{OVERVIEW ON THE PRESENT SitUATION: THE STATUS OF STUDENT AFFAIRS ADMINISTRATORS' OCCUPATIONAL WELL-BEING AND ITS INFLUENCING FACTORS}

\section{A. The Status of University Counselors' Occupational Well- being in China}

Through the investigation on the subjective well-being of 211 counselors of universities in Fujian province and the interview with 50 counselors, Liao Shenji believes that the subjective well-being of the counselors is in a middle level but shows an increasing trend year by year. ${ }^{3} \mathrm{Wu} \mathrm{Xi}$ randomly selected 60 counselors from more than 30 independent universities in Wuhan City as the subject of investigation and researched their occupational well-being based on the three dimensions: overall life satisfaction, negative emotion and positive emotion, then she concluded that the counselors' life satisfaction was lower than the middle level, their positive emotional sense was slightly higher than the middle level, and their negative emotional sense is slightly lower than the middle level. So she believed that the overall situation of the counselor's occupational wellbeing is slightly lower than the middle level. ${ }^{4} \mathrm{He}$ Haiyan used a qualitative research method to make deep interviews

teachers $[\mathrm{J}]$. Journal of Occupational and Organizational Psychology, 2004,(77):365-375.

Ma Ting. Absence of Occupational Well-Being in University Counselors and Its and Reconstruction [J]. School Party Building and Ideological Education, 2011(8):93.

Liao Shenji, Zhang Benyu, Lin Fei. Study on Subjective WellBeing of University Counselors [J]. Strait Science, 2008(9):14-17.

$\mathrm{Wu} \mathrm{Xi}$. Analysis on the Occupational Well-Being of Counselors in Independent Colleges [J].Contemporary Economy, 2010(11):56-57. with 11 young counselors of four universities in Chongqing City. By probing into the main factors that affect the counselor's occupational well-being, she discovered that "the interest in the career of the counselor", "the success and growth of the students" and "the students' respect and affection" are the main positive factors for the young counselors to gain occupational happiness. However, compared with these positive emotional experiences, respondents are more like to talk more about the negative factors that affect their occupational well-being, which have greatly dispelled their occupational well-being.

Almost all of these empirical studies show that the current college counselor's occupational well-being is not high.

\section{B. Analysis on the Factors Influencing the Counselor's Occupational Well-being}

As "a kind of continuous and stable inner happiness sense", a counselor's occupational well-being is the reaction result between the counselor's subjectivity and the environmental objectivity, and its influential factors are diverse.

\section{Psychological Factors (Professional Identity, Life Attitude, Achievement Motivation, Etc.)}

The level of subjective professional identity has a direct influence on the counselor's occupational well-being. Because of the disidentification of the society, the professional teachers, the family members and a part of students, some counselors' professional identity sense is also very low. Counselors' attitude towards life and work can also affect the sense of occupational well-being. Compared to professional teachers, civil servants and other professional staffs, counselors have more workload, longer working hours and lower recognition of works. Under this contrast, the counselors' self-esteem will be bruised and affect the occupational well-being. The level of achievement motivation is also one of the psychological factors that affect counselor's occupational well-being. A person's achievement needs determine the level of his/her achievement motivation, and the level of achievement motivation determines the expected ambition goal. There can be no occupational wellbeing when a counselor's own level of achievement falls below their expected ambition.

\section{Demographic Factors (Gender, Age, Etc.)}

Desmarais and Curtis believe that, generally speaking, men intend to gain more recognition and benefits than women for the same contribution. When the same tasks are performed and the rewards are assessed, women are always more likely to underestimate themselves than men. ${ }^{6}$ And the age difference also can affect a counselor's occupational

\footnotetext{
He Haiyan. Study on the Major Factors Affecting the Occupational Well-being of Young Counselors in Universities $[\mathrm{J}]$. Contemporary Youth Research, 2011(10):77-80.

Desmarais, Serge; Curtis, James. Gender and Perceived Pay Entitlement: Testing for Effects of Experience with Income [J].Journal of Personality and Social Psychology, 1997,(9):141-150.
} 
well-being. Counselors with different age intervals may have different attitudes towards work and life, different levels of ability to work, and different expectations for career development. It's not hard to explain why many empirical studies show that male counselors have lower occupational well-being than that of women, and young counselors have lower occupational well-being than that of older counselors.

\section{E. Cultural Factors (Institutional Guarantee, Traditional Habits, Values, Etc.)}

The promotion of occupational well-being depends on the institutional guarantee, and the scientific and reasonable institutional design guarantees the construction and development of the counselors' ranks, which is the essential factor for the counselor's occupational well-being promotion. Traditional habits are the second cultural factor. A German study shows that the phenomenon of people feeling happy is not accidental but depends on many of the details of life and personal life habits to a large extent and the good habits make people possess a more happy feeling in daily life. For counselors, developing a good kind of living habits, including active learning, keeping harmony with other people and timely self-regulation, will help improve the occupational well-being. The values are the third cultural factor. This kind of values can be dividedly understood as self-values and social values. From the individual aspect, the promotion of the counselor's self-values can improve the individual enthusiasm towards the work, enhance the occupational well-being, and hence promote the social values. From the social aspect, the promotion of the social values of counselors can improve their social recognition and social status, promote the social attention to the career of counselors and improve the moral and material return of counselors, so as to promote the occupational well-being.

\section{F. Economic Factors (Employment Status, Income Level, Etc.)}

The employment status here mainly refers to the working situation of counselors in different universities and colleges, departments and posts. Between general universities, adult colleges and private colleges, counselors' service target, work content, job requirements and remuneration and others will be different. Even in different departments of the same school, these aspects of the counselor's work will be different, which will affect the counselor's professional identity and occupational well-being. The economic situation and income level obviously affect the occupational well-being, but such effect is not a simple positively linear relationship. Some of counselors enjoying poor remuneration, but their happiness is not low, and some other highly paid counselors are worried all day. Compared with the income level, the mental aspect, especially the success and growth of the students, has a greater impact on the counselor's career well-being and plays a decisive role for it.

\section{G. Social Factors (Education Level, Family Environment, Etc.)}

At present, most of the 211 and 985 universities have set a threshold of master degree or above in the selection of counselors, so counselors' degrees will also affect their occupational well-being. In contrast, the higher the counselor's qualification is, the more opportunities for development. Family factor plays an important role in counselor's occupational well-being. Family members' trust, respect, understanding and support can help the counselor experience happiness in the intimate and harmonious family atmosphere after complex works, so as to learn to love his/her own life.

\section{H. Political Factors (Democratic Rights, Opportunities for Participation, Etc.)}

Occupational well-being is an all-round thing, so a counselor's democratic rights and participation opportunities in the work will also frequently and directly affect his/her work self-esteem and identity. In some universities, counselors are merely engaged in work, but lack initiatives and voting rights, which results that some counselors mock themselves as "a simple working robot." This has also led to the reluctance of many counselors to pursue lifelong service for student works, and such mental instability results in a decline in the occupational well-being.

The above six factors are not independent but are interrelated, mutually-influenced and mutually-restrictive. They jointly produce an impact on the counselor's occupational well-being.

\section{REALIZATION PATH: A STRATEGY FOR IMPROVING THE OCCUPATIONAL WELL-BEING BASED ON CAREER DEVELOPMENT NEEDS}

Because of the above six factors related to the counselors and their environment, the current counselors' occupational well-being is not optimistic. The author believes that, in order to obtain happiness from the occupation, in addition to the self-adjustment of counselors to keep a good professional mentality, the promotion of the ranks' occupational and professional construction is also particularly important.

\section{A. The Promotion of the Counselor Ranks' Occupational and Professional Construction Is a Guarantee}

It needs to promote the occupational and professional development of counselors' ranks, so that counselors can really find the prospect of career development, have some expectations on career development, which is the key to improve the occupational well-being of counselors. This kind of occupational and professional construction can be focused on several aspects:

1) Clarify the role and position:The counselors' dual identities have revealed the nature of the counselors' work and broadened the career development channels of the counselors, but on the other hand, there are some problems being involved in this, such as the conflict of job roles, the difficulty of professional identity, the dilemma of career development and the transition of jobs. In multiple identities, it is of great significance to define the core identity of the counselors, to clarify the role of the counselors, to strengthen the function of the counselors and to exert the 
initiative of the counselors, which will be critical for building a high-quality, moral and demonstrative work team.

2) Establish a career area: Counselors are both teachers and cadres. As a result, they should not only conduct ideological and political education for students, but also provide students with professional learning guidance, which also puts forward a requirement on the counselors for possessing high quality and corresponding professional knowledge. Therefore, it should strengthen the discipline construction, train the specialized personnel, set up the discipline system, the curriculum system and the teaching material system of the counselor's profession, and really take the counselor's work as a career area to be built. For example, in the United States, there are doctorates of "university student counselors", "student affairs management" and other similar professional doctorates for specializing and training professional counselors' ranks.

3) Perfect institutional guarantee: It needs to further adhere to high-starting-point and strict-quality entry mechanism, high-standard and high-quality training mechanism, highly-demanding and highly pragmatic management mechanism as well as high-level and highly incentive development mechanism, so as to provide a strong institutional guarantee for their professional development.

\section{B. The Counselor's Own Job Positioning and Professional Mentality Adjustment Is the Key}

"A continuous and stable sense of happiness" is a counselor's own subjective feeling in accordance with his or her own standards. Therefore, in order to improve the counselor's occupational well-being, the counselor's own job positioning and professional mentality adjustment is the key. Counselors should know how to cherish, how to learn to be satisfied, how to consider the success and growth of the students as the greatest achievement of their work to reach the unified realization of the personal value and the social value, so as to provide an internal power support for obtaining occupational well-being.

\section{CONCLUSION}

Therefore, the external conditions for the occupational and professional development of counselors should be constantly perfected, the counselor's own job positioning should be reasonably clarified and the professional mentality should be constantly adjusted. Under the joint action of internal and external improvements, the work efficiency of counselors is able to be improved, their sense of belonging can be enhanced, and hence counselors may be able to fully experience the occupational well-being.

\section{REFERENCES}

[1] Ye Lan. A Novel Exploration on Teachers' Roles and Development [M]. Beijing: Education Science Press, 2001.

[2] Liu Huihui. Research on the Well-being of University Counselors and its Influencing Factors [D]. Shenyang: Shenyang Normal University, 2011.
[3] Li Jinhua, Cui Jian. Occupational Well-being of University Counselors and Its Realization [J]. Journal of College Advisor, 2010(1).

[4] Ma Ting. Absence of Occupational Well-Being in University Counselors and Its and Reconstruction [J]. School Party Building and Ideological Education, 2011(8). 